\title{
Entry, financing, and bankruptcy decisions: The limited liability effect
}

\author{
Jyh-Bang Jou, Associate Professor of Economics* \\ Graduate Institute of National Development, National Taiwan University, \\ No. 1 Roosevelt Rd. Sec. 4, Taipei, Taiwan 106, Republic of China
}

\begin{abstract}
A firm, which has a privileged right to undertake an irreversible investment project, simultaneously determines whether to exercise this project and also how many bonds to issue in the presence of demand uncertainty. The firm will not exercise the project until its net value from investing immediately equals its option value from delaying investment. The firm's choice of debt levels balances the tax advantage of debt against a cost associated with the event of bankruptcy. The effects of uncertainty, asset specificity, and the costs to purchase capital later on a firm's entry, financing, and bankruptcy decisions are examined and compared with those in the literature. () 2001 Bureau of Economic and Business Research, University of Illinois. All rights reserved.
\end{abstract}

JEL classification: G13; G32

Keywords: Bankruptcy; Irreversible investment; Limited liability

\section{Introduction}

A central topic in financial economics is to examine how the limited liability of equity affects a firm's investment and financing decisions. This topic is first addressed by Myers (1977) who suggests that a firm's existing debt load causes it to underinvest. Consequently, debt financing imposes an agency cost resulting from the conflict of interest between equity and debt holders over the timing of the investment. This agency cost, together with the benefit of debt (for example, the tax advantage), determines the firm's choice of debt levels.

* Tel.: +886-2-23630231-3590; fax: +886-2-23679684.

E-mail address: jbjou@ccms.ntu.edu.tw (J.-B. Jou).

1062-9769/01/\$ - see front matter (C) 2001 Bureau of Economic and Business Research, University of Illinois. All rights reserved. PII: S 1062-9769(00)00062-4 
Subsequently, Brander and Lewis (1986) set up a two-period model where debt financing involves a tradeoff between the agency cost considered by Myers and the strategic benefit arising from interactions between firms in a duopolistic market. Recently this topic has continuously drawn attention to several articles that apply the real options approach (for example, Fries et al., 1997; Mauer and Ott, 2000; Mello et al., 1995). However, these articles set up rather complicated models, and therefore, yield results mainly through numerical examples. In this article, while still applying the real options approach, I will build a simplified model to gain insights on the relationship between capital asset characteristics and the optimal level of debt.

This article differs from previous works in four respects. ${ }^{1}$ First, the previous works typically assume that the investment costs are irreversible. In contrast, this article assumes that the investment costs are partially reversible. Accordingly, this article is able to examine how changes in the magnitude of partial capital reversibility affect a firm's choice of debt levels. Second, the previous works typically assume that upon bankruptcy, a firm's debtholders receive a value equal to the value of the firm unlevered. In contrast, this article assumes that a firm's debtholders receive the salvage value of the firm upon bankruptcy, thus greatly simplifying analysis. Third, the previous works typically assume that debt has been issued before the investment option is exercised. This leads to two kinds of costs: (i) the agency cost arising from the conflict of interest between equity and debt holders over the timing of exercising the investment option as considered by Myers (1977); and (ii) the cost associated with the event of bankruptcy. In contrast, this article abstracts from the first kind of cost by assuming that debt is issued upon exercising the investment option. This not only simplifies analysis but may be more realistic for a firm with a higher percentage of growth options. ${ }^{2}$ Finally, the previous works typically assume that the investment costs are constant over time. However, the investment costs may rise over time because of limited land, reserves of natural resources, or the need for a permit that is in short supply (Abel et al., 1996). This article allows for this by assuming that the investment costs follow a deterministic exponentially growing process, thus being able to link the costs from purchasing capital later with a firm's choice of debt levels.

This article assumes that a firm owns a privileged right to undertake an investment project and can simultaneously finance this project by issuing bonds without a stated maturity. After exercising the investment project, at each instant the firm receives one unit of output, it incurs operating costs, and must pay coupons to debtholders that are tax deductible. The output price is stochastic over time. If the output price falls short of the sum of the operating costs and coupon payments, then equityholders can cover this shortfall by injecting funds. However, they may cease to inject funds, and instead choose an output price on behalf of themselves to declare bankruptcy. This imposes a cost on debtholders, but equityholders should bear this cost because debtholders will rationally anticipate equityholders' future behavior. As a result, the firm will choose a debt level that equates the tax advantage of debt to this cost. ${ }^{3}$ In addition, the firm will exercise the investment project at an output price that equates its net value from investing immediately to its option value from delaying investment.

Previous works provide predictions on the impacts of asset characteristics on a firm's investment decisions and/or its financing decision(s). These include: first, both Abel et al., 
(1996) and Dixit and Pindyck (1998) suggest that a firm that does not issue bonds will have a higher incentive to invest if in the future the firm either purchases capital or resells installed capital at a higher price. Second, Dixit (1989), McDonald and Siegel (1986) and Pindyck (1988) suggest that a firm that does not issue bonds will have a lower incentive to invest if it faces greater uncertainty. Third, Williamson (1988) suggests that a firm will take on less debt if it incurs higher sunk costs of investment resulting from higher asset specificity. Fourth, Myers (1977) suggests that a firm will take on less debt if it incurs lower costs from delaying investments that result in higher growth option values. Finally, Mauer and Ott (2000) suggest that a firm which faces greater uncertainty will expand debt capacity by waiting for a better state to exercise the investment option. This article yields several results that differ from these previous works because the underlying assumptions of this article differ from those of them.

This article is organized as follows. Section 2 constructs the basic model to examine a firm's entry, financing, and bankruptcy decisions. Section 3 makes the results in Section 2 more vivid through numerical examples. The last section makes conclusions and also suggestions for future research.

\section{The model}

This section builds a model which extends the model commonly used in real options literature (for example, Fries et al., 1997; Mauer and Ott, 2000; and Mello et al., 1995). Consider a firm that has a privileged right to undertake an investment project. The firm incurs an initial investment cost, denoted by $K(t)$, which is expected to grow at an exponential rate $\alpha$, that is,

$$
d K(t)=\alpha K(t) d t .
$$

The term $\alpha$ may be positive, zero, or negative, where a positive $\alpha$ implies that the firm incurs higher costs to invest later. The firm can finance the investment project by issuing bonds without a stated maturity and will not adjust its leverage until the moment of bankruptcy. After exercising this project, at each instant, the firm receives one unit of output, it incurs a fixed amount of operating costs, denoted by $w$, and must pay a fixed amount of coupons to debtholders, denoted by $b$. Suppose that $P(t)$ denotes the output price, then net earnings to equityholders are given by

$$
(1-\tau)(P(t)-w-b),
$$

where $\tau$ is the corporate income tax rate. Eq. (2) indicates that losses are fully offset, which is an approximation of the current U.S. tax system that allows for a partial loss offset through both carry-back and carry-forward provisions. Eq. (2) also indicates that coupon payments are tax-deductible, thus creating a tax advantage to leverage. The output price $P(t)$ follows a geometric Brownian motion given by

$$
d P(t)=P(t) \mu d t+P(t) \sigma d \Omega(t),
$$


for constants $\mu$ and $\sigma$ and a standard Wiener Process $\Omega(t)$. The salvage value of the installed capital stock is assumed to be equal to $\lambda K(t)$, where $0 \leq \lambda<1$. The firm's assets are assumed to transfer from equityholders to debtholders upon bankruptcy. Consequently, the residual value of the firm after bankruptcy is equal to the salvage value of the installed capital stock. ${ }^{4}$ Both this residual value and the initial investment cost $K(t)$ are assumed to be free of taxation. For simplicity, depreciation of capital is also neglected. The firm is also assumed to be unable to temporarily suspend its operation, thus precluding the "moth-balling" of productive activities such as that considered by Brennan and Schwartz (1984) and Mello and Parsons (1992). Finally, the firm's equityholders are assumed to have access to unlimited external resources. ${ }^{5}$

Let us start from $t=0$, and denote both $P$ as $P(t)$ and $K$ as $K(t)$ evaluated at $t=0$. Suppose that $\rho$ denotes the firm's (risk-adjusted) discount rate and both $\beta_{1}$ and $\beta_{2}$ denote the positive and negative roots in the quadratic equation

$$
\phi(\beta)=-\frac{\sigma^{2}}{2} \beta(\beta-1)-\beta(\mu-\alpha)+\rho-\alpha=0 .
$$

Eq. (4) can be rewritten as

$$
\phi(\beta)=\frac{(\rho-\alpha)\left(\beta_{1}-\beta\right)\left(\beta_{2}-\beta\right)}{\beta_{1} \beta_{2}} .
$$

Applying Itô's Lemma and using the risk-adjusted valuation method (for example, Dixit 1989 ) yields the firm's value to equityholders, $V^{e}(P, b)$, and that to debtholders, $V^{d}(P, b)$, as respectively given by (see the Appendix)

$$
\begin{aligned}
& V^{e}(P, b)=\frac{(1-\tau) P}{(\rho-\mu)}-\frac{(1-\tau)(w+b)}{\rho}+a_{1} P^{\beta_{1}} K^{1-\beta_{1}}+a_{2} P^{\beta_{2}} K^{1-\beta_{2}}, \\
& V^{d}(P, b)=\frac{b}{\rho}+c_{1} P^{\beta_{1}} K^{1-\beta_{1}}+c_{2} P^{\beta_{2}} K^{1-\beta_{2}},
\end{aligned}
$$

where all $a_{1}, a_{2}, c_{1}$, and $c_{2}$ are constants to be determined. In what follows, I will also assume that $\rho>\mu$ and $\rho>\alpha$. The former assures that $V^{e}(P, b)$ in (5) is convergent while the latter assures that the user cost of capital, $(\rho-\alpha) K$, is positive. Combining these two assumptions implies that $\beta_{1}>1$ and $\beta_{2}<0$. Eqs. (5) and (6) have the following meanings. The first term net of the second term on the right-hand side of (5) is the after-tax expected present value of the firm's value to equityholders assuming that the firm never goes bankrupt. The sum of the last two terms on the right-hand side of (5) is the equityholders' value of the option to declare bankruptcy later. The first term on the right-hand side of (6) is the expected present value of coupon payment of debt assuming that the firm never goes bankrupt. The sum of the last two terms on the right-hand side of (6) is the potential loss of debt value resulting from the possibility of insolvency in the future. 


\subsection{Bankruptcy decisions}

Following Leland (1998) and Mauer and Ott (2000), I will assume that it is prohibitively costly to write and enforce contracts that ensure a firm's manager to maximize total firm value after the firm issues bonds. Accordingly, the firm's manager may maximize levered equity value upon bankruptcy because equity has limited liability (see, for example, Brander and Lewis, 1986; Jensen and Meckling, 1976; Myers, 1977). If the output price falls short of the sum of the operating costs and coupon payments, then net earnings given by (2) will be negative. Equityholders can then inject funds to cover this shortfall. However, they may cease to inject funds and instead choose an output price on behalf of themselves, denoted by $\mathrm{P}_{*}$, to declare bankruptcy (Black and Cox, 1976; Fries et al., 1997; Leland, 1994).

The constants $a_{1}$ and $a_{2}$ in (5), and both $c_{1}$ and $c_{2}$ in (6), and the term $P_{*}$ should be solved simultaneously. First, two boundary conditions are given by:

$$
\begin{aligned}
& \lim _{P \rightarrow \infty} V^{e}(P, b)=(1-\tau)\left[\frac{P}{\rho-\mu}-\frac{w+b}{\rho}\right], \\
& \lim _{P \rightarrow \infty} V^{d}(P, b)=\frac{b}{\rho} .
\end{aligned}
$$

Condition (7) holds because default becomes irrelevant as the output price is extremely high, thus yielding $a_{1}=0$ in (5). Condition (8) indicates that as the output price is extremely high, the firm's debtholders will almost surely receive coupon payments $b$ at each instant, thus yielding $c_{1}$ $=0$ in (6). Second, in the absence of arbitrage, the following two conditions must be satisfied:

$$
\begin{aligned}
& V^{e}\left(P_{*}, b\right)=0, \\
& V^{d}\left(P_{*}, b\right)=\lambda K .
\end{aligned}
$$

Conditions (9) and (10) respectively indicate that at the output price that triggers bankruptcy, the firm's value to equityholders is equal to zero and that to debtholders is equal to the salvage value of the installed capital stock. Solving Eq. (9) yields

$$
a_{2}=(1-\tau)\left[\frac{(w+b)}{\rho}-\frac{P_{*}}{(\rho-\mu)}\right] P_{*}^{-\beta_{2}} K^{\beta_{2}-1} .
$$

Solving Eq. (10) yields

$$
c_{2}=\left(\lambda K-\frac{b}{\rho}\right) P_{*}^{-\beta_{2}} K^{\beta_{2}-1} .
$$

Finally, the following smooth-pasting condition must be satisfied (see, for example, Fries et al., 1997; Mauer and Ott, 2000): 


$$
\frac{\partial V^{e}\left(P_{*}, b\right)}{\partial P}=0 .
$$

Condition (13) is the first-order condition that requires the default price be chosen to maximize levered equity value.

Substituting both $a_{1}=0$ and $a_{2}$ in (11) into (13) yields the results stated in Proposition 1.

Proposition 1: Suppose that a firm's claims to equityholders are maximized upon bankruptcy. The critical level of the output price that triggers bankruptcy immediately, $P_{*}$, will then be given by

$$
P_{*}=\pi \cdot(w+b),
$$

where

$$
\pi=\frac{\beta_{2}(\rho-\mu)}{\left(\beta_{2}-1\right) \rho} .
$$

Corollary 1 follows from Proposition 1.

Corollary 1: $P_{*}$ will be lower as either $\alpha$ or $\sigma$ is higher.

Proof. See the Appendix.

Proposition 1 indicates that the exit trigger price, $P_{*}$, will be equal to a factor, $\pi$ in (14), multiplied by the Marshallian full cost of disinvesting, $w+b$. Corollary 1 indicates that both a higher purchase price of capital in the future (a higher $\alpha$ ) and greater uncertainty (a higher $\sigma)$ are associated with a lower level of the exit trigger price, and thus a lower incentive to exit the market. This is because both raise the firm's value to equityholders given by (5) since (i) the equityholders' value of the option to declare bankruptcy later (that is, the sum of the last two terms on the right-hand side of (5)) is higher, and (ii) the equityholders' value assuming that the firm never goes bankrupt (that is, the first term net of the second term on the right-hand side of (5)) remains unchanged.

If the firm never went bankrupt, then the firm's debtholders would receive the expected present value of coupon payment equal to $b / \rho$, the first term on the right-hand side of (6). However, when the firm's equityholders choose a price equal to $P_{*}$ in (14) to declare bankruptcy, then the firm's debtholders will only receive the residual value of the firm, $\lambda K$. Consequently, upon bankruptcy, the firm's debtholders will lose a value equal to $b / \rho-\lambda K$. Debt financing thus involves a cost associated with the event of bankruptcy. This bankruptcy cost has two components (Fries et al., 1997; Mauer and Ott, 2000): (i) the loss of the interest tax shield of debt in bankruptcy; and (ii) the dead-weight loss of firm value in bankruptcy because the investment costs are not fully recoverable since the term $\lambda$ is smaller than one. This bankruptcy cost, together with the tax shield benefit, determines the firm's choice of debt levels. 


\subsection{Investment and financing decisions}

In what follows, I will assume that a firm simultaneously makes investment and financing decisions. Accordingly, the firm will maximize total firm value by choosing both an investment option exercise strategy and a debt level. Suppose that $V(P, b)$ denotes total firm value, that is, the sum of both $V^{e}(P, b)$ in Eq. (5) and $V^{d}(P, b)$ in Eq. (6). Substituting both $a_{1}=0$ and $a_{2}$ in (11) into (5), and both $c_{1}=0$ and $c_{2}$ in (12) into (6), and then summing up $V^{e}(P, b)$ and $V^{d}(P, b)$ yields total firm value as given by

$$
\begin{aligned}
V(P, b)= & {\left[( 1 - \tau ) \left(\left(\frac{P}{(\rho-\mu)}-\frac{(w+b)}{\rho}\right)+\left(\frac{(w+b)}{\rho}-\frac{P_{*}}{(\rho-\mu)}\right)\right.\right.} \\
& \left.\left.\cdot\left(\frac{P}{P_{*}}\right)^{\beta_{2}}\right)\right]+\frac{b}{\rho}-\left(\frac{b}{\rho}-\lambda K\right)\left(\frac{P}{P_{*}}\right)^{\beta_{2}},
\end{aligned}
$$

where the terms inside brackets are the value of equity while the remaining terms are the value of debt.

As suggested by real options literature (Dixit and Pindyck, 1994), the interaction of uncertainty and irreversibility indicates that the firm has an option value to invest later, denoted by $F(P, b)$. Applying the risk-adjusted valuation method and using Itô's Lemma yields $F(P, b)$ as given by (see the Appendix)

$$
F(P, b)=g_{1} P^{\beta_{1}} K^{1-\beta_{1}}+g_{2} P^{\beta_{2}} K^{1-\beta_{2}} .
$$

The constant $g_{2}$ is equal to zero because the following boundary condition must be satisfied:

$$
\lim _{P \rightarrow 0} F(P, b)=0 \text {. }
$$

Condition (17) indicates that the firm's option value to invest later will become worthless as the output price is extremely low. The other constant $g_{1}$, together with the entry trigger price, denoted by $P^{*}$, and the choice of coupon payments, denoted by $b^{*}$, must be determined simultaneously. First, given the firm's choice of coupon payments, two optimal conditions, the value-matching and smooth-pasting conditions, must be satisfied at $P=P^{*}$. They are respectively given by

$$
\begin{aligned}
& F\left(P^{*}, b^{*}\right)=V\left(P^{*}, b^{*}\right)-K, \\
& \frac{\partial F\left(P^{*}, b^{*}\right)}{\partial P}=\frac{\partial V\left(P^{*}, b^{*}\right)}{\partial P} .
\end{aligned}
$$

Condition (18) indicates that the firm will not exercise the investment project unless its net value from investing immediately, $V\left(P^{*}, b^{*}\right)-K$, equals its option value to invest later, $F\left(P^{*}, b^{*}\right)$. In addition, condition (19) is required to rule out the possibility of any arbitrage profits. Second, given the firm's investment option exercise strategy, the firm's choice of 
coupon payments, $b^{*}$, is obtained by setting the derivative of total firm value, $V\left(P^{*}, b^{*}\right)$ in Eq. (15), with respect to $b$ equal to zero, that is,

$$
\frac{\partial V\left(P^{*}, b^{*}\right)}{\partial b}=0
$$

Substituting (15) into (18) and (19), multiplying (19) by $P^{*} /\left(-\beta_{1}\right)$, adding the result into (18), and then rearranging yields

$$
W\left(P^{*}, b^{*}\right)=\frac{P^{*}}{\beta_{1}} \frac{\partial V\left(P^{*}, b^{*}\right)}{\partial P}-V\left(P^{*}, b^{*}\right)+K=0 .
$$

Eq. (21) suggests that the term $W\left(P^{*}, b^{*}\right)$ is equal to the firm's option value to later invest minus its net value from investing immediately. The explicit form of (21) is given by

$$
\begin{aligned}
{\left[\frac{w}{\rho}+K-\frac{\tau\left(w+b^{*}\right)}{\rho}\right] } & +\left[\left(1-\frac{\beta_{2}}{\beta_{1}}\right)\left(\frac{P^{*}}{P_{*}}\right)^{\beta_{2}}\left(\frac{(1-\tau)\left(w+b^{*}\right)}{\rho\left(\beta_{2}-1\right)}+\frac{b^{*}}{\rho}-\lambda K\right)\right] \\
+ & {\left[\frac{P^{*}(1-\tau)\left(1-\beta_{1}\right)}{(\rho-\mu) \beta_{1}}\right]=0 . }
\end{aligned}
$$

The terms inside the first pair of brackets are the after-tax costs of investment, and therefore, are positive. The terms inside the second pair of brackets arise because the firm's equityholders have the option to declare bankruptcy later, that is, because both $a_{2}$ in (5) and $c_{2}$ in (6) are nonzero. These terms will be positive if $\lambda=w=0$.

Eq. (21) implicitly defines the dependence of $P^{*}$ on $b^{*}$, as suggested by Proposition 2.

Proposition 2: A firm will be more hesitant to exercise the investment project (that is, the entry trigger price $P^{*}$ will be higher) as the firm takes on more debt.

Proof. Totally differentiating $W\left(P^{*}, b^{*}\right)=0$ in (21) with respect to $b^{*}$ and then rearranging yields

$$
\frac{d P^{*}}{d b^{*}}=\frac{\Delta_{12}}{-\Delta_{11}}
$$

where

$$
\begin{aligned}
& \Delta_{12}=\frac{\partial W\left(P^{*}, b^{*}\right)}{\partial b}=\frac{-\tau \beta_{2}}{\rho \beta_{1}}>0, \\
& \Delta_{11}=\frac{\partial W\left(P^{*}, b^{*}\right)}{\partial P}=\beta_{2}\left[\frac{(1-\tau)}{(\rho-\alpha)}-\frac{1}{P^{*}}\left(\frac{w}{\rho}+K-\frac{\tau\left(w+b^{*}\right)}{\rho}\right)\right] .
\end{aligned}
$$

In deriving the expression for $\Delta_{11}$ in (22") I have used the relationship $\phi(1)=(\rho-\alpha)\left(\beta_{1}\right.$ $-1)\left(\beta_{2}-1\right) /\left(\beta_{1} \beta_{2}\right)=\rho-\mu$ defined in Eq. $\left(4^{\prime}\right)$. For $P^{*}$ to be an interior solution of Eq. (21), it is required that $\Delta_{11}$ in (22") be negative, or equivalently, the terms inside brackets in $\left(22^{\prime \prime}\right)$ be larger than zero, that is, 


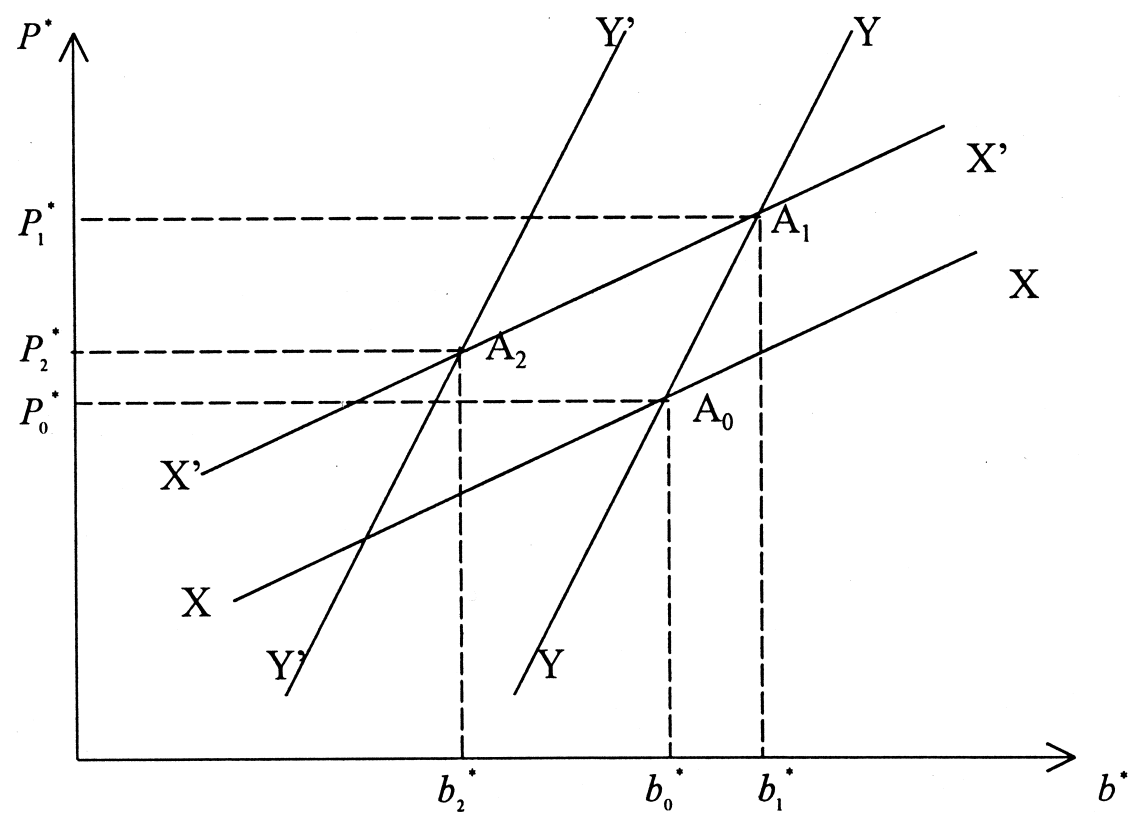

Fig. 1. A rise in the irreversibility of investment (a fall in $\lambda$ ).

$$
(1-\tau) P^{*}>(\rho-\alpha)\left(\frac{w}{\rho}+K-\frac{\tau\left(w+b^{*}\right)}{\rho}\right) .
$$

Condition (22'") indicates that the critical level of the after-tax price that triggers entry should be higher than the flow-equivalent after-tax costs of investment. I will assume this holds in what follows. Given that $\Delta_{11}<0$ and $\Delta_{12}>0$, as shown by (22'), the sign of $d P^{*} / d b^{*}$ in (22) is thus positive. This completes the proof.

In Fig. 1 line $\mathrm{XX}$ depicts the positive relationship between the entry trigger price, $P^{*}$, and the firm's choice of coupon payments, $b^{*}$, stated in Proposition 2. The intuition behind this positive relationship is as follows. As a firm takes on more debt, its net value by investing immediately, the right-hand side of (18), is reduced by more than is its option value to later invest, the left-hand side of (18). Accordingly, the firm's incentive to enter the market will be lower because the entry trigger price is higher.

Now consider the first-order condition for the firm's choice of debt levels defined in (20), which has the explicit form given by

$$
\left[\frac{\tau}{\rho}\left(1-\left(\frac{P^{*}}{P_{*}}\right)^{\beta_{2}}\right)\right]-\left[\frac{-\beta_{2}}{\left(w+b^{*}\right)}\left(\frac{b^{*}}{\rho}-\lambda K\right)\left(\frac{P^{*}}{P_{*}}\right)^{\beta_{2}}\right]=0 .
$$

The terms inside the first pair of brackets in $\left(20^{\prime}\right)$ are positive and represent the (probabilityweighted) marginal tax benefit. The terms inside the second pair of brackets in $\left(20^{\prime}\right)$ are positive both because $\beta_{2}$ is negative and also because the face value of debt, $b^{*} / \rho$, is greater than the salvage value of the installed capital stock, $\lambda K$. These terms represent the net 
marginal bankruptcy cost arising from the bankruptcy point chosen by the equityholders. Eq. $\left(20^{\prime}\right)$ suggests that, a firm's choice of debt levels balances the marginal tax benefit against this marginal bankruptcy cost. ${ }^{6}$ This equation also implicitly defines the dependence of $b^{*}$ on $P^{*}$, as suggested by Proposition 3.

Proposition 3: A firm will issue more bonds as the firm is more hesitant to exercise the investment project (that is, as the entry trigger price $P^{*}$ is higher).

Proof. Totally differentiating $\partial V\left(P^{*}, b^{*}\right) / \partial b=0$ in (20) with respect to $P^{*}$ yields

$$
\frac{d b^{*}}{d P^{*}}=\frac{\Delta_{21}}{-\Delta_{22}}>0,
$$

where

$$
\begin{aligned}
\Delta_{21} & =\frac{\partial^{2} V\left(P^{*}, b^{*}\right)}{\partial P \partial b}=\left[\frac{-\pi \beta_{2}}{\rho P^{*}}\left(\frac{P^{*}}{P_{*}}\right)^{\beta_{2}}\right]+\left[\frac{-\tau \beta_{2}}{\rho P^{*}}\left(1-\left(\frac{P^{*}}{P_{*}}\right)^{\beta_{2}}\right)\right]=\frac{-\tau \beta_{2}}{\rho P^{*}}>0, \\
\Delta_{22} & =\frac{\partial^{2} V\left(P^{*}, b^{*}\right)}{\partial b^{2}} \\
& =\frac{\beta_{2}}{\left(w+b^{*}\right)}\left(\frac{P^{*}}{P_{*}}\right)^{\beta_{2}}\left[\frac{\tau}{\rho}+\frac{1}{\left(w+b^{*}\right)}\left(\frac{w}{\rho}+\lambda K-\beta_{2}\left(\frac{b^{*}}{\rho}-\lambda K\right)\right)\right] \\
& <0 .
\end{aligned}
$$

The sign of $d b^{*} / d P^{*}$ in (23) is positive both because $\Delta_{21}>0$, as suggested by $\left(23^{\prime}\right)$, and because $\Delta_{22}<0$, as suggested by $\left(23^{\prime \prime}\right)$. This completes the proof.

In Fig. 1 line YY depicts the positive relationship between the firm's choice of coupon payments, $b^{*}$, and the entry trigger price, $P^{*}$, stated in Proposition 3 . The intuition behind this positive relationship is as follows. The signs of the terms inside the first and second pairs of brackets in $\left(23^{\prime}\right)$ are both positive. Both respectively indicate that a firm waiting for a higher output price to exercise the investment project will enjoy a larger marginal tax benefit and bear a lower marginal bankruptcy cost. Consequently, a firm that waits for a higher output price to exercise the investment project will issue more bonds.

For $P^{*}$ and $b^{*}$ to be interior solutions of both Eqs. (20) and (21), it is also required that

$$
\Delta=\Delta_{11} \Delta_{22}-\Delta_{12} \Delta_{21}>0 .
$$

Condition (24) requires that in Fig. 1 line YY be steeper than line XX. In what follows, I will assume this holds.

\subsection{Comparative static results}

In the following, I will examine how the firm's investment, financing, and bankruptcy decisions are affected by changes in the sunk costs of investment $(\lambda)$, the costs to invest later $(\alpha)$, or the size of uncertainty $(\sigma)$. One main result is stated in Proposition 4. 
Proposition 4: As a firm incurs a higher sunk cost to exercise the investment project ( $\lambda$ is lower), its incentive to enter the market will be lower, while both its incentives to issue bonds and exit the market may be higher, lower, or unchanged. ${ }^{7}$

Proof. See the Appendix.

The intuition behind Proposition 4 is as follows. Let us start from an initial equilibrium point $\mathrm{A}_{0}$, the intersection of lines $\mathrm{XX}$ and $\mathrm{YY}$ in Fig. 1, which has an entry trigger price $P_{0}{ }^{*}$, and a choice of coupon payments $b_{0}{ }^{*}$. As suggested by (A9), given a firm's choice of debt levels, as the firm incurs a higher sunk cost to exercise the investment project ( $\lambda$ is lower), its net value by investing immediately is lower while its option value to invest later is higher. Accordingly, the firm will have a lower incentive to invest because the entry trigger price becomes higher. In Fig. 1 line XX which shifts upward to line $X^{\prime} X^{\prime}$ captures this effect. The intersection of lines $\mathrm{X}^{\prime} \mathrm{X}^{\prime}$ and $\mathrm{YY}$ is at point $\mathrm{A}_{1}$, where the entry trigger price $P_{1}{ }^{*}>P_{0}{ }^{*}$ and the choice of coupon payments $b_{1}{ }^{*}>b_{0} *$. In addition, as suggested by (A11), given a firm's investment option exercise strategy, as the firm incurs a higher sunk cost to exercise the investment project, its marginal tax benefit is unchanged, while its marginal bankruptcy cost is higher. Accordingly, line YY will shift to the left, but this shift will never make the new entry trigger price lower than the initial one, $P_{0}{ }^{*}$, as suggested by (A12). Nevertheless, the new choice of coupon payments may be either higher than, equal to, or lower than the initial one, $b_{0}{ }^{*}$ (In Fig. 1 line YY shifting to line Y'Y' depicts the case for the last possibility). Finally, after the firm issues bonds, equity holders are not concerned with debt holders. Accordingly, given the firm's choice of coupon payments, a change in the sunk costs of investment $(\lambda)$ will not affect the firm's bankruptcy decision, as suggested by $P_{*}$ in (14) that is independent of $\lambda$. However, as suggested by (A16), a change in the sunk costs of investment will exhibit an ambiguous effect on both the firm's choice of debt levels, and therefore, its bankruptcy decision.

Abel et al. (1996) indicate that a firm that does not issue bonds will have a lower incentive to invest if the firm incurs higher sunk costs of investment by reselling installed capital at a lower price. With debt financing, an induced effect will arise: the firm's choice of coupon payments will be ambiguously affected, and therefore, its incentive to invest will be also ambiguously affected. Nevertheless, this induced effect is always dominated by the former one. The result in Proposition 4 thus resembles the result in Abel et al. (1996).

Williamson (1988) argues that firm-specific assets are more likely to require discretionary investment. Due to the limited liability of equity, debt financing prevents firms from making the appropriate investment to realize the full-value of these assets. Consequently, a higher sunk cost of investment resulting from higher asset specificity will lead to less debt. ${ }^{8}$ However, in my analysis, as a firm incurs a higher sunk cost of investment, its incentive to issue bonds may be higher, lower, or unchanged. The reason for this difference is as follows. In my framework, a higher sunk cost of investment (a lower $\lambda$ ) will affect a firm's incentive to issue bonds through two channels. First, the entry trigger price $P^{*}$ will be higher. As suggested by $\left(23^{\prime}\right)$, a higher entry trigger price, in turn, will lead to both a lower marginal bankruptcy cost and a higher marginal tax benefit. Second, given the firm's choice of entry trigger price $P^{*}$, the marginal bankruptcy cost, those terms inside the second pair of brackets 
in $\left(20^{\prime}\right)$, will be higher. Putting these two effects together may yield a result that differs from that of Williamson.

Consider the impacts of changes in both the cost to purchase capital later $(\alpha)$ and also the size of uncertainty $(\sigma)$ on a firm's entry and financing decisions. All comparative static results are ambiguous, as suggested by the Appendix.

Dixit and Pindyck (1998) indicate that a firm that does not issue bonds will have a lower incentive to invest if the firm purchases capital at a lower price in the future. However, with debt financing this result no longer holds. The reason is as follows. In my analysis, a lower purchase price of capital in the future will affect a firm's incentive to invest through three channels. First, assuming that the firm never goes bankrupt, the firm's value from investing immediately will remain unchanged while its option value from delaying investment will be higher, thus lowering its incentive to invest. This effect, which is captured by the negative terms inside the last pair of brackets in (A17), resembles the effect considered by Dixit and Pindyck. Second, allowing the firm to have the option to later declare bankruptcy, the firm's incentive to invest will be ambiguously affected. The sum of the terms inside the first three pairs of brackets in (A17), which can be positive, negative, or zero captures this effect. Finally, as suggested by (A18'), the firm's choice of coupon payments, and therefore, its induced effect on the firm's incentive to invest are both ambiguously affected. My result differs from that of Dixit and Pindyck because the last two effects introduced by debt financing may either offset or reinforce the first one.

Capital assets that are less costly to purchase later will have a higher growth option value (Abel et al., 1996). However, a higher growth option value exhibits an ambiguous relationship with the choice of debt levels. ${ }^{9}$ The reason is as follows. As a firm purchases capital at a lower price in the future, its incentive to issue bonds will be affected through two channels. First, the entry trigger price $P^{*}$ may be higher, lower, or unchanged. Correspondingly, the firm's incentive to issue bond will be higher, lower, or unchanged, respectively, as suggested by $\left(23^{\prime}\right)$. Second, the firm will be less likely to fall into bankruptcy $\left(\partial P_{*} / \partial \alpha>0\right)$, and the term $\beta_{2}$ will be lower $\left(\partial \beta_{2} / \partial \alpha>0\right)$. Accordingly, the firm's incentive to issue bonds can be higher, lower, or unchanged, as suggested by (A18). Combining these two effects thus yields an indefinite impact on the firm's incentive to issue bonds.

In real options literature such as Dixit (1989), McDonald and Siegel (1986) and Pindyck (1988), a firm that does not issue bonds will be more hesitant to invest if uncertainty is greater. However, with debt financing this result no longer holds. The reason is as follows. In my analysis, an increase in uncertainty will affect a firm's incentive to invest through three channels. First, assuming that the firm never goes bankrupt, its incentive to invest will be lower, as suggested by the positive terms inside the last pair of brackets in (A17). This resembles the effect considered by those studies. Second, allowing the firm to have the option to declare bankruptcy later, the firm's incentive to invest will be ambiguously affected, as suggested by the sum of the terms inside the first three pairs of brackets in (A17). Finally, as suggested by (A18), the firm's incentive to issue bonds, and therefore, its induced effect on the firm's incentive to invest will both be ambiguously affected. My result differs from the result of those studies because the last two effects introduced by debt financing may not be in line with the first one.

Finally, in my analysis, an increase in uncertainty affects a firm's incentive to issue bonds 


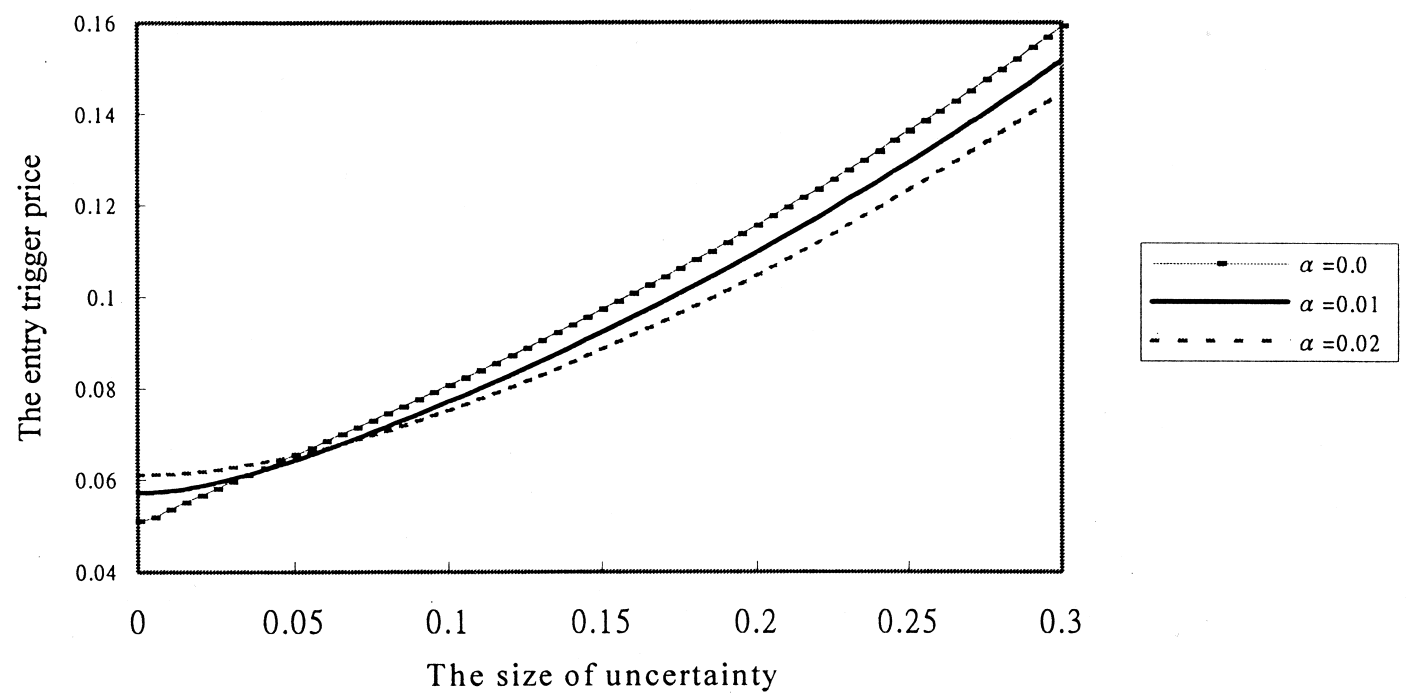

Fig. 2. The entry trigger price $\left(P^{*}\right)$ versus the size of uncertainty $(\sigma)$.

through two channels. First, as suggested by (A17), the firm's incentive to invest may be higher, lower, or unchanged. As a result, its debt capacity will be contracted, expanded, or unchanged, respectively, as suggested by $\left(23^{\prime}\right)$. Second, given the firm's investment option exercise strategy, the firm's debt capacity will be ambiguously affected, as suggested by (A18). Putting these two effects together suggests that an increase in uncertainty generates an indefinite effect on the firm's incentive to issue bonds. This contrasts with that of Mauer and Ott (2000); they assume that a firm may finance with debt to expand its scale of operations and find that debt capacity is generally increasing in uncertainty.

\section{Numerical examples}

I make the results in the last section more vivid through numerical analysis. The base-case parameter values I choose are as follows. The investment cost $K=1$, the operating $\operatorname{cost} w=$ 0 , the size of irreversibility $(1-\lambda)=1$, the (risk-adjusted) discount rate $\rho=5 \%$ per year, the expected return from investing $\mu=0$, the corporate tax rate $\tau=25 \%$, the expected growth rate of the purchase price of capital $\alpha=0,1 \%$, or $2 \%$ per year, and the size of uncertainty $\sigma$ varies from 0 to $30 \%$ per year. In other words, I consider one polar case where both the operating cost is negligible and the installed capital stock has no resale value.

Given these base-case parameters, Figs. 2, 3, and 4 respectively show the effects of changes in the size of uncertainty $(\sigma)$ on the entry trigger price $\left(P^{*}\right)$, the exit trigger price $\left(P_{*}\right)$, and the face value of debt $\left(b^{*} / \rho\right)$. Five main conclusions are as follows. First, greater uncertainty induces a firm to be more cautious in both entering and exiting the market both because $P^{*}$ is higher, as shown by Fig. 2, and also because $P_{*}$ is lower, as shown by Fig. 3 . This resembles the "hysterisis" effect emphasized by real options literature that ignores debt 


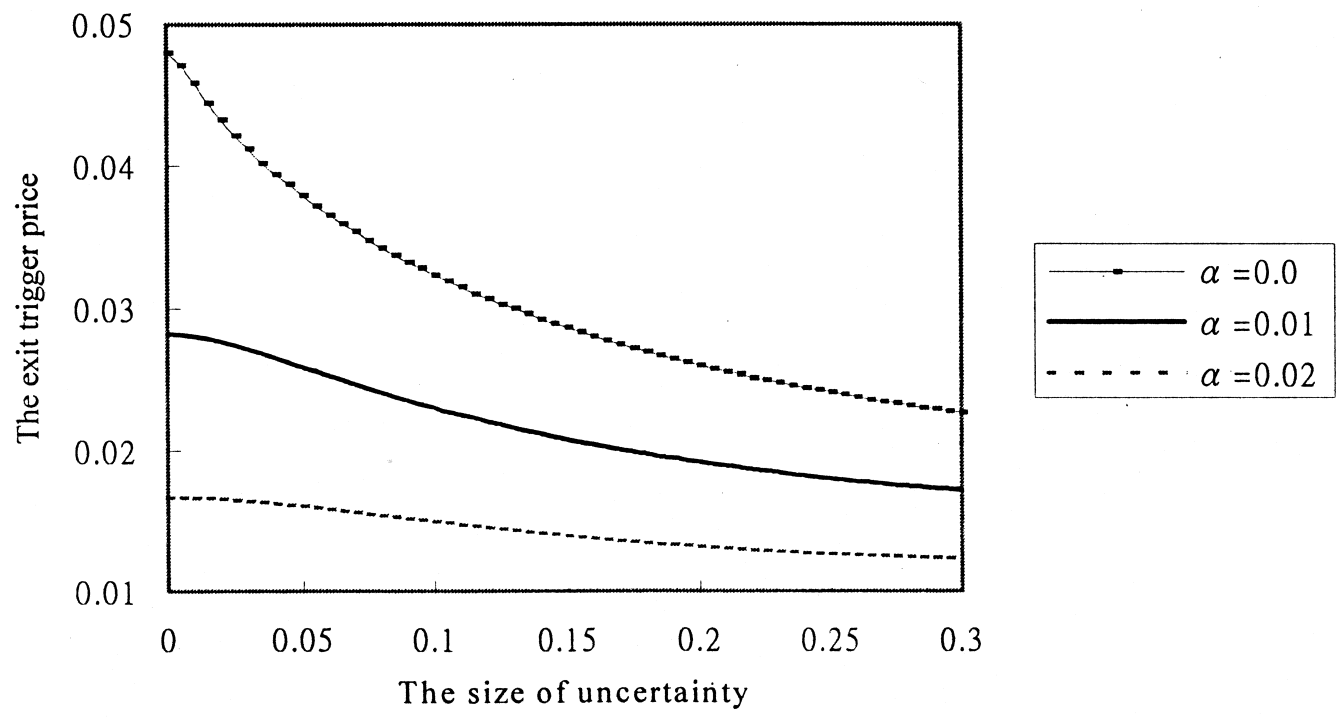

Fig. 3. The exit trigger price $\left(P_{*}\right)$ versus size of uncertainty $(\sigma)$.

financing (see, for example, Dixit and Pindyck, 1994). Second, as shown by Fig. 4, debt capacity is generally increasing in uncertainty, thus resembling that in Mauer and Ott (2000). The only exception appears in the case where both the purchase price of capital is constant over time $(\alpha=0)$ and uncertainty is very small $(0<\sigma<8 \%$ per year), but this case seems to be economically unreasonable. Third, as shown by Fig. 3, a firm that purchases capital at a higher price in the future ( $\alpha$ is higher) tends to be more reluctant to exit the market because

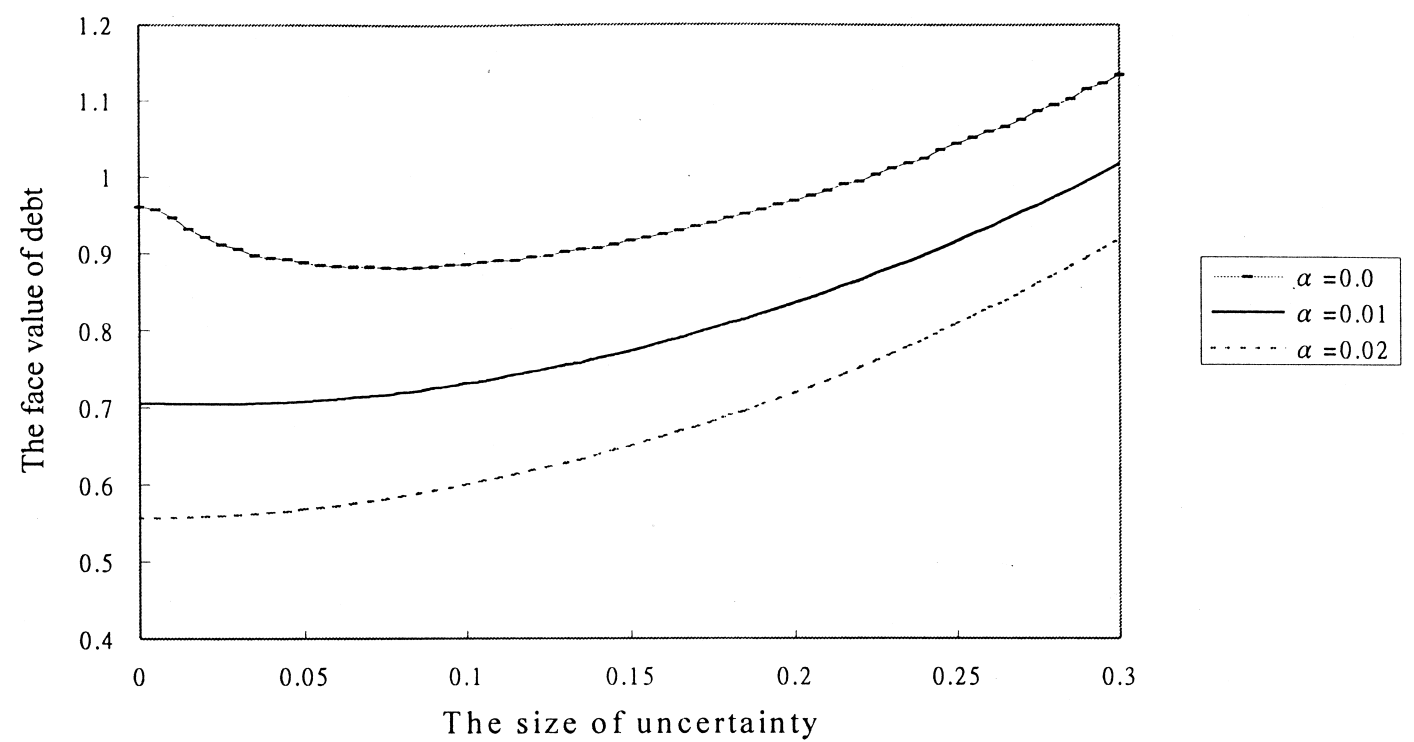

Fig. 4. The face value of debt $(b * / \rho)$ versus the size of uncertainty $(\sigma)$. 
the exit trigger price is lower. Fourth, as suggested by Fig. 2, a firm that purchases capital at a higher price in the futures tends to invest earlier when uncertainty is large enough (when $\sigma>6.5 \%$ per year). This conclusion resembles that in Abel et al. (1996) which ignores debt financing. Finally, a firm that purchases capital at a higher price in the future tends to issue fewer bonds, as shown by Fig. 4.

\section{Conclusions}

This article adopts the real options approach to investigate interactions of investment and financing decisions. This article assumes that debt financing creates a tax advantage but leads to a cost associated with the event of bankruptcy. The effects of uncertainty, asset specificity, and the costs from purchasing capital later on a firm's entry, financing, and bankruptcy decisions are examined and compared with those in the literature.

Several extensions can be made in future research. First, one may examine whether the results of this article still hold for an oligopolistic industry (for example, Baldursson, 1998). Second, this article considers that debt financing involves a tradeoff between the tax benefit and the bankruptcy cost resulting from the limited liability of equity. Several other considerations are possible. For example, bonds may convey private information to capital markets, mitigate adverse selection effects, or affect the outcome of corporate control contests (for example, Harris and Raviv, 1991), and agency costs may result from the "asset substitution" problem (for example, Jensen and Meckling, 1976; Leland, 1994 and 1998). Third, one may consider several ways to resolve the agency problem of limited liability of equity (see, for example, Mauer and Ott, 2000). These include (i) shortening debt maturity (Myers, 1977), and (ii) offering strategic debt service by equityholders (Mella-Barral and Perraudin, 1997). Finally, one may allow a firm to continuously adjust both its capacity and leverage by incorporating debt financing into the study by either Bertola and Caballero (1994) or Dixit and Pindyck (1998).

\section{Notes}

1. This article also focuses on issues differing from those of the previous works. For example, Fries et al. (1997) focus on the relationship between debt value in competitive equilibrium and the elasticity of demand for the total output. Mauer and Ott (2000) measure the size of the agency costs due to limited liability and discuss how this measurement is related to both credit spreads on risky debt and optimal capital structure. Mello et al. (1995) show that a firm can use forward contracts to hedge exchange rate exposure so as to reduce the agency cost due to limited liability.

2. The author thanks one anonymous referee for pointing out this.

3. This resembles the standard literature on financial structure (for example, Kraus and Litzenberger, 1973).

4. All Black and Cox (1976), Leland (1994) and Merton (1974) assume that this value follows a geometric Brownian motion, while Mello and Parsons (1992) assume that 
this value follows a geometric Brownian motion plus the option value associated with liquidation possibilities. Fries et al. (1997) encompass these assumptions by assuming that this value is a non-negative function of the output price.

5. Fries et al. (1997) consider both this case and the case where the firm's equityholders have access to limited external resources.

6. Eq. $\left(20^{\prime}\right)$ can be used to compare the choice of debt levels for a monopolized firm with that chosen by a competitive firm. It has been noted by Fries et al. (1997) that competitive pressure will induce competitive firms entering the industry to reduce leverage until the point at which the face value of debt, $b * / \rho$, equals the salvage value of the installed capital stock, $\lambda K$. However, Eq. $\left(20^{\prime}\right)$ suggests that $b^{*} / \rho>\lambda K$ for a firm that has a monopolized right to undertake an irreversible investment project. This yields the following result: a firm having a privileged right to undertake an irreversible investment project will issue more bonds than those issued by a competitive firm in equilibrium.

7. The resale price of capital is a fixed ratio of its purchase price, and thus has the same evolution as that of its purchase price. This contrasts with Dixit and Pindyck (1998) in which the evolution of the resale price of capital may differ from that of its purchase price.

8. Dasgupta and Sengupta (1993) allow bilateral bargaining between a firm and its workers, and demonstrate that Williamson's conjecture may not be valid in general.

9. This result cannot be directly compared with that of Myers (1977), which states that a firm's leverage is inversely related to its growth option value. This is because I abstract from the agency cost arising from the conflict of interest between equity and debt holders over the optimal timing of exercising the investment option.

\section{Acknowledgments}

I would like to thank the editor (J. E. Finnerty), two anonymous reviewers, Szu-Lang Liao, and seminar participants at both the National Cheng-chi University and the 7th Conference on the theories and practices of security and financial markets held at the National Sun Yat-Sen University in December 1998. Financial support under Grant NSC-88-2416-H002-013 from the National Science Council, Executive Yuan, R.O.C., is gratefully acknowledged.

\section{Appendix}

$<$ Derivation of $V^{e}(P, b), \mathrm{V}^{e}(P, b)$ and $\mathrm{F}(P, b)>$

Treating $V^{e}(P, b)$ as an asset value, and using both (1) and (2), and according to Itô's Lemma yields its expected capital gain as given by

$$
E \frac{d V^{e}(P, b)}{d t}=\frac{1}{2} \sigma^{2} P^{2} \frac{\partial^{2} V^{e}(P, b)}{\partial P^{2}}+\mu P \frac{\partial V^{e}(P, b)}{\partial P}+\alpha K \frac{\partial V^{e}(P, b)}{\partial K}
$$


This expected capital gain plus the dividend $(1-\tau)(\mathrm{P}-w-b)$ should be equal to the normal return $\rho V^{e}(P, b)$ to prevent any arbitrage profits from arising. This yields the differential equation

$$
\begin{gathered}
\frac{1}{2} \sigma^{2} P^{2} \frac{\partial^{2} V^{e}(P, b)}{\partial P^{2}}+\mu P \frac{\partial V^{e}(P, b)}{\partial P}+\alpha K \frac{\partial V^{e}(P, b)}{\partial K} \\
+(1-\tau)(P-w-b)-\rho V^{e}(P, b)=0 .
\end{gathered}
$$

A particular solution to Eq. (A2) is given by

$$
V^{e}(P, b)=(1-\tau)\left(\frac{P}{\rho-\mu}-\frac{w+b}{\rho}\right) .
$$

The complementary solution to Eq. (A2) involves terms in the form $\mathrm{P}^{\beta} K^{1-\beta}$, for $\beta$ a solution to the characteristic equation defined in Eq. (4). The general solution to equation (A2), which is composed of both the particular and complementary parts, is shown by (5).

Similarly, the solution for $V^{d}(\mathrm{P}, \mathrm{b})$, the value of debt, satisfies the differential equation

$$
\frac{1}{2} \sigma^{2} P^{2} \frac{\partial^{2} V^{d}(P, b)}{\partial P^{2}}+\mu P \frac{\partial V^{d}(P, b)}{\partial P}+\alpha K \frac{\partial V^{d}(P, b)}{\partial K}+b-\rho V^{d}(P, b)=0 .
$$

A particular solution to Eq. (A4) is given by

$$
V^{d}(P, b)=\frac{b}{\rho} .
$$

The general solution to Eq. (A4) is thus given by (6). Following similar procedures as above and noting that the dividend for a waiting firm is zero yields the solution for $F(P, b)$ as given by (16).

$<$ Proof of Corollary $1>$

$$
\frac{\partial P_{*}}{\partial \alpha}=\frac{-(\rho-\mu)(w+b)}{\rho\left(\beta_{2}-1\right)^{2}} \frac{\partial \beta_{2}}{\partial \alpha}<0,
$$

since $\frac{\partial \beta_{2}}{\partial \alpha}=\frac{\partial \phi\left(\beta_{2}\right) / \partial \alpha}{-\partial \phi\left(\beta_{2}\right) / \partial \beta}>0$,

where $\partial \phi\left(\beta_{2}\right) / \partial \alpha=\beta_{2}-1<0$, and $\partial \phi\left(\beta_{2}\right) / \partial \beta>0$.

$$
\frac{\partial P_{*}}{\partial \sigma}=\frac{-(\rho-\mu)(w+b)}{\rho\left(\beta_{2}-1\right)^{2}} \frac{\partial \beta_{2}}{\partial \sigma}<0,
$$

since $\frac{\partial \beta_{2}}{\partial \sigma}=\frac{\partial \phi\left(\beta_{2}\right) / \partial \sigma}{-\partial \phi\left(\beta_{2}\right) / \partial \beta}>0$,

where $\partial \phi\left(\beta_{2}\right) / \partial \sigma=-\sigma \beta_{2}\left(\beta_{2}-1\right)<0$, and $\partial \phi\left(\beta_{2}\right) / \partial \beta_{2}>0$. 
$<$ Proof of Proposition $4>$

Totally differentiating $W\left(P^{*}, b^{*}\right)=0$ in (21) with respect to $\lambda$ yields

$$
\begin{aligned}
& \frac{\partial W\left(P^{*}, b^{*}\right)}{\partial P} \frac{d P^{*}}{d \lambda}+\frac{\partial W\left(P^{*}, b^{*}\right)}{\partial b} \frac{d b^{*}}{d \lambda}+\frac{\partial W\left(P^{*}, b^{*}\right)}{\partial \lambda}=0, \\
& \text { where } \frac{\partial W\left(P^{*}, b^{*}\right)}{\partial \lambda}=-K\left(1-\frac{\beta_{2}}{\beta_{1}}\right)\left(\frac{P^{*}}{P_{*}}\right)^{\beta_{2}}<0 .
\end{aligned}
$$

Totally differentiating $\partial V\left(P^{*}, b^{*}\right) / \partial b=0$ in (20) with respect to $\lambda$ yields

$$
\frac{\partial^{2} V\left(P^{*}, b^{*}\right)}{\partial b \partial P} \frac{d P^{*}}{d \lambda}+\frac{\partial^{2} V\left(P^{*}, b^{*}\right)}{\partial b^{2}} \frac{d b^{*}}{d \lambda}+\frac{\partial^{2} V\left(P^{*}, b^{*}\right)}{\partial b \partial \lambda}=0,
$$

where $\frac{\partial^{2} V\left(P^{*}, b^{*}\right)}{\partial b \partial \lambda}=\frac{\beta_{2} K}{\left(w+b^{*}\right)}\left(\frac{P^{*}}{P_{*}}\right)^{\beta_{2}}>0$.

Solving both Eqs. (A8) and (A10) simultaneously yields

$$
\begin{aligned}
& \frac{d P^{*}}{d \lambda}=\frac{\Delta_{1}}{\Delta}<0, \\
& \frac{d b^{*}}{d \lambda}=\frac{\Delta_{2}}{\Delta} \gtreqless 0,
\end{aligned}
$$

because condition (24) implies that $\Delta>0$,

$$
\begin{aligned}
\Delta_{1} & =\frac{\partial W\left(P^{*}, b^{*}\right)}{\partial \lambda} \frac{\partial^{2} V\left(P^{*}, b^{*}\right)}{\partial b^{2}}+\frac{\partial W\left(P^{*}, b^{*}\right)}{\partial b} \frac{\partial^{2} V\left(P^{*}, b^{*}\right)}{\partial b \partial \lambda} \\
& =\frac{\beta_{2} K}{\left(w+b^{*}\right)}\left(\frac{P^{*}}{P_{*}}\right)^{\beta_{2}}\left[\left(1-\frac{\beta_{2}}{\beta_{1}}\right)\left(\frac{P^{*}}{P_{*}}\right)^{\beta_{2}} \frac{1}{\left(w+b^{*}\right)}\left(\frac{w}{\rho}+\lambda K\right)+\frac{\tau}{\rho}\right]<0, \\
\Delta_{2} & =\frac{\partial W\left(P^{*}, b^{*}\right)}{\partial P} \frac{\partial^{2} V\left(P^{*}, b^{*}\right)}{\partial b \partial \lambda}+\frac{\partial^{2} V\left(P^{*}, b^{*}\right)}{\partial P \partial b} \frac{\partial W\left(P^{*}, b^{*}\right)}{\partial \lambda} \\
& =\frac{-\beta_{2} K}{P^{*}}\left(\frac{P^{*}}{P_{*}}\right)^{\beta_{2}}\left[\frac{\beta_{2}}{\left(w+b^{*}\right)}\left(\frac{-(1-\tau)}{(\rho-\alpha)} P^{*}+\frac{w}{\rho}+K\right)-\frac{\tau}{P}\left(\beta_{2}+1-\frac{\beta_{2}}{\beta_{1}}\right)\right] \gtreqless 0 .
\end{aligned}
$$

Differentiating $P_{*}$ in (14) with respect to $\lambda$ yields

$$
\frac{d P_{*}}{d \lambda}=\frac{(\rho-\mu) \beta_{2}}{P\left(\beta_{2}-1\right)} \frac{d b^{*}}{d \lambda} \gtreqless 0 .
$$

This completes the proof.

$<$ Proof of the impacts of $\alpha$ or $\sigma$ on both $W\left(P^{*}, b^{*}\right)$ and $\partial V\left(P^{*}, b^{*}\right) / \partial b>$ 
Let $z$ represent $\alpha$ or $\sigma$. Differentiating $W\left(P^{*}, b^{*}\right)$ in $(21)$ with respect to $z$ yields

$$
\begin{aligned}
\frac{\partial W\left(P^{*}, b^{*}\right)}{\partial z}= & {\left[-\frac{1}{\beta_{1}^{2}}\left(\beta_{1} \frac{\partial \beta_{2}}{\partial z}-\beta_{2} \frac{\partial \beta_{1}}{\partial z}\right)\left(\frac{P^{*}}{P_{*}}\right)^{\beta_{2}}\left(\frac{(1-\tau)\left(w+b^{*}\right)}{\rho\left(\beta_{2}-1\right)}+\frac{b^{*}}{\rho}-\lambda K\right)\right] } \\
& +\left[\left(1-\frac{\beta_{2}}{\beta_{1}}\right)\left(\frac{P^{*}}{P_{*}}\right){ }^{\beta_{2}} \ln \left(\frac{P^{*}}{P_{*}}\right)\left(\frac{(1-\tau)\left(w+b^{*}\right)}{\rho\left(\beta_{2}-1\right)}+\frac{b^{*}}{\rho}-\lambda K\right) \frac{\partial \beta_{2}}{\partial z}\right] \\
& +\left[\left(1-\frac{\beta_{2}}{\beta_{1}}\right)\left(\frac{P^{*}}{P_{*}}\right)^{\beta_{2}} \frac{1}{\left(\beta_{2}-1\right)}\left(\frac{b^{*}}{\rho}-\lambda K\right) \frac{\partial \beta_{2}}{\partial z}\right]+\left[\left(\frac{-P^{*}(1-\tau)}{\beta_{1}^{2}(\rho-\mu)} \frac{\partial \beta_{1}}{\partial z}\right] \gtreqless 0\right.
\end{aligned}
$$

where $\partial \beta_{2} / \partial z>0, \partial \beta_{1} / \partial \alpha>0$, and $\partial \beta_{1} / \partial \sigma<0$.

The sum of the terms inside the first three pairs of brackets is derived by differentiating the terms inside the second pair of brackets in $\left(21^{\prime}\right)$ with respect to $\mathrm{z}$, and thus denotes the impact of a rise in $\mathrm{z}$ on $W\left(P^{*}, b^{*}\right)$ that results from the equityholders' option value to later declare bankruptcy. The terms inside the last pair of brackets are derived by differentiating the terms inside the last pair of brackets in $\left(21^{\prime}\right)$ with respect to $\mathrm{z}$, and therefore, denote the impact of a rise in $z$ on $W\left(P^{*}, b^{*}\right)$, as captured by the study on real options that ignores debt financing. If $z=\alpha$, then the terms inside the first, third, and last pairs of brackets are all negative while the terms inside the second pair of brackets are positive. If $\mathrm{z}=\sigma$, then the terms inside the second and last pairs of brackets are both positive, the terms inside the third pair of brackets are negative, while the terms inside the first pair of brackets can be positive, negative or zero.

Differentiating $\partial V\left(P^{*}, b^{*}\right) / \partial b$ given by the left-hand side of $\left(20^{\prime}\right)$ with respect to $z$ yields

$$
\begin{aligned}
\frac{\partial^{2} V\left(P^{*}, b^{*}\right)}{\partial b \partial z}=\left[-\frac{\tau}{\rho}\left(\frac{P^{*}}{P_{*}}\right)^{\beta_{2}}\left(\ln \frac{P^{*}}{P_{*}}+\frac{1}{\left(\beta_{2}-1\right)}\right) \frac{\partial \beta_{2}}{\partial z}\right] \\
+\left[\frac{\beta_{2}}{\left(w+b^{*}\right)}\left(\frac{b^{*}}{\rho}-\lambda K\right)\left(\frac{P^{*}}{P_{*}}\right)^{\beta_{2}}\left(\ln \frac{P^{*}}{P_{*}}+\frac{1}{\left(\beta_{2}-1\right)}\right) \frac{\partial \beta_{2}}{\partial z}\right] \\
+\left[\frac{1}{\left(w+b^{*}\right)}\left(\frac{b^{*}}{\rho}-\lambda K\right)\left(\frac{P^{*}}{P_{*}}\right)^{\beta_{2}} \frac{\partial \beta_{2}}{\partial z}\right] \gtreqless 0,
\end{aligned}
$$

where $\partial \beta_{2} / \partial z>0$. The terms inside the first pair of brackets are the effect of a change in $\mathrm{z}$ on the marginal tax benefit, while the sum of the terms inside the last two pairs of brackets is the effect of a change in $z$ on the marginal bankruptcy cost. The terms inside the last pair of brackets are positive, while the terms inside either the first or second pair of brackets can be positive, negative, or zero. Eq. (A18) can also be rewritten as

$$
\frac{\partial^{2} V\left(P^{*}, b^{*}\right)}{\partial b \partial z}=\frac{\tau}{\rho}\left[\frac{1}{\left(1-\beta_{2}\right)}-\ln \frac{P^{*}}{P_{*}}+\frac{1}{\left(-\beta_{2}\right)}\left(1-\left(\frac{P^{*}}{P_{*}}\right)^{\beta_{2}}\right)\right] \frac{\partial \beta_{2}}{\partial z} \gtreqless 0 .
$$




\section{References}

Abel, A. B., Dixit, A. K., Eberly, J. C., \& Pindyck, R. S. (1996). Option, the value of capital, and investment. Quarterly Journal of Economics, 111, 753-777.

Baldursson, F. M. (1998). Irreversible investment under uncertainty in oligopoly. Journal of Economic Dynamics and Control, 22, 627-644.

Bertola, G., \& Caballero, R. (1994). Irreversibility and aggregate investment. Review of Economic Studies, 61, 223-246.

Black, F., \& Cox, J. (1976). Valuing corporate securities: some effects of bond indenture provisions. Journal of Finance, 31, 351-367.

Brander, J. A., \& Lewis, T. R. (1986). Oligopoly and financial structure: the limited liability effect. American Economic Review, 76, 956-970.

Brennan, M. J., \& Schwartz, E. S. (1984). Valuation of corporate claims. Journal of Finance, 39, 593-607.

Dasgupta, S., \& Sengupta, K. (1993). Sunk investment, bargaining and choice of capital structure. International Economic Review, 34, 203-220.

Dixit, A. K. (1989). Entry and exit decisions under uncertainty. Journal of Political Economy, 97, 620-638.

Dixit, A. K., \& Pindyck, R. S. (1994). Investment under uncertainty. Princeton, New Jersey: Princeton University Press.

Dixit, A. K., \& Pindyck, R. S. (1998). Expandability, reversibility, and optimal capacity choice. NBER Working Paper, 6373.

Fries, S., Miller, M., \& Perraudin, W. (1997). Debt in industry equilibrium. Review of Financial Studies, 10, $39-67$.

Harris, M., \& Raviv, A. (1991). The theory of capital structure. Journal of Finance, 46, 297-355.

Jensen, M. C., \& Meckling, W. H. (1976). Theory of the firm: managerial behavior, agency costs, and capital structure. Journal of Financial Economics, 4, 177-203.

Kraus, A., \& Litzenberger, R. H. (1973). A state-preference model of optimal financial leverage. Journal of Finance, 28, 1213-1252.

Leland, H. E. (1994). Corporate debt value, bond covenants, and optimal capital structure. Journal of Finance, 49, 1213-1252.

Leland, H. E. (1998). Agency costs, risk management, and capital structure. Journal of Finance, 53, 1213-1244.

Mauer, D. C., \& Ott, S. H. (2000). Agency costs, investment policy and optimal capital structure: the effect of growth options. In M. J. Brennan \& L. Trigeorgis (Eds.), Project flexibility, agency and market competition: new developments in the theory and application of real options (pp. 151-179). London: Oxford University Press.

McDonald, R., \& Siegel, D. (1986). The value of waiting to invest. Quarterly Journal of Economics, 101, 707-727.

Mello, A. S., \& Parsons, J. E. (1992). The agency costs of debt. Journal of Finance, 47, 1887-1904.

Mello, A. S., Parsons, J. E., \& Triantis, A. J. (1995). An integrated model of multinational flexibility and financial hedging. Journal of International Business, 39, 27-51.

Mella-Barral, P., \& Perraudin, W. (1997). Strategic debt services. Journal of Finance, 52, 531-556.

Merton, R. C. (1974). On the pricing of corporate debt: the risk structure of interest rates. Journal of Finance, 29, 449-470.

Myers, S. (1977). Determinants of corporate borrowing. Journal of Financial Economics, 5, 147-175.

Pindyck, R. S. (1988). Irreversible investment, capacity choice, and the value of the firm. American Economic Review, 78, 969-985.

Williamson, O. (1988). Corporate finance and corporate governance. Journal of Finance, 43, 567-592. 